\title{
Procedimento de ensaio para juntas soldadas em barras de titânio tipo protocolo branemark
}

\author{
Josivan Lopes de Morais Júnior ${ }^{[1]}$, Francisco Edson Nogueira Fraga ${ }^{[2]}$ e Alan de Queiroz Fernandes ${ }^{[3]}$ \\ [1] Universidade Federal Rural do Semi-Árido; josivanjunior2803@gmail.com \\ [2] Universidade Federal Rural do Semi-Árido, nfraga@ufersa.com \\ [3] Universidade São Leopoldo Maadic; dralandentista@gmail.com \\ Recebido: 08/07/2020; \\ Aceito: $28 / 07 / 2020$; \\ Publicado: 11/09/2020.
}

Resumo: Com a crescente demanda por próteses sobre implantes do tipo protocolo e suas inúmeras vantagens em comparação com outros tipos de próteses dentárias, a indústria odontológica procura métodos de confecção dessas próteses com custos mais baixos para que uma maior população de pacientes seja atendida. Dentre os métodos mais utilizados de confecção das barras metálicas tipo protocolo estão a fundição e a fresagem. Outro método que vem ganhando atenção é a soldagem de barras de titânio ASTM F67, através do processo Tungsten Inert Gas (TIG). Para validar uniões soldadas, dentre outros critérios de controle, faz-se necessário a realização de ensaios mecânicos para avaliar propriedades mecânicas dessas juntas soldadas. No presente trabalho, foi proposto um procedimento de soldagem de corpos de prova com geometria em $\mathrm{T}$ (semelhante às uniões observadas na confecção dos protocolos), seguido de ensaio em tração adaptado, para validar essas juntas soldadas em T, confeccionadas a partir de barras de Titânio no mesmo diâmetro utilizado na fabricação desses protocolos. O procedimento proposto, de soldagem de corpo de prova em T e ensaio em tração adaptado, se mostrou satisfatório para avaliar as juntas soldadas. Complementarmente, em ensaios preliminares para validar o ensaio adaptado para o corpo de prova em $\mathrm{T}$, demonstraram que as juntas soldadas testadas já apresentaram bons resultados de tensão máxima em tração, com relação a tensão de escoamento do metal base.

Palavras-chave: Próteses; Protocolo; Titânio ASTM F67; Soldagem TIG; Ensaio de tração.

Abstract: With a growing demand for prostheses on protocol-type implants and their advantages over comparison with other types of dental prostheses, a dental industry uses methods of making these prostheses with lower costs for a larger population of patients, is served. Among the most used methods for making metal bars, the type of protocol is founded and updated. Another method that is gaining attention is the welding of ASTM F67 titanium bars, through the Tungsten Inert Gas (TIG) process. To validate welded joints, among other control criteria, it is necessary to carry out mechanical tests to evaluate the mechanical properties of these welded joints. In the present work, a procedure for welding specimens with $\mathrm{T}$ geometry (similar to joints observed in the making of protocols) was adopted, followed by adaptation tests to validate these $\mathrm{T}$-welded joints, made from titanium bars. in the same diameter used in the manufacture of these protocols. The proposed procedure, the welding of the specimen in the adapted test, proved satisfactory to evaluate the welded joints. Complementarily, in preliminary tests to validate or in an adapted test for the $\mathrm{T}$ specimen, it has been demonstrated that the welded joints already present good results of maximum stress, in relation to the yield stress of the metal base.

Key-words: Prostheses; Titanium; TIG Welding; Tensile Test.

\section{INTRODUÇÃO}


$\mathrm{N}$

as últimas décadas, a indústria do titânio teve um grande desenvolvimento, tanto na indústria aeroespacial e naval, quanto na indústria química, devido a suas características difíceis de se obter em aço ou alumínio, como por exemplo, a alta resistência à corrosão, baixa densidade (material leve) [1, 2, 3], boa soldabilidade, e biocompatibilidade, uma característica muito visada na indústria ortopédica e odontológica [1, 3, 4] e a osseointegração, de tal modo que nunca houve registro de rejeição de um implante dentário de titânio na história.

A osseointegração, quando referida à odontologia, está relacionada com a técnica de implantes dentários, quando um osso vivo ordenado entra em contato direto com a superfície de um implante [5]. Essa propriedade do Titânio, aliada as outra citadas anteriormente, faz com que esse material seja o mais utilizado em implantes dentários.

O implante dentário de titânio é fixado no tecido ósseo bucal, substituindo as raízes dentárias perdidas ou ausentes. Sobre estes implantes uma estrutura metálica é produzida servindo de sustentação para a próteses dentárias. No caso de barras de titânio soldadas, é realizada a solda entre cilindros, ou pilares (abutment), e segmentos de barras (entre 2,5 e 3,5 mm de diâmetro) personalizados, sendo todas essas partes constituídas por titânio (puro ou liga).

Segundo Atoui (2008), "uma prótese fixa sustentada por uma ou mais pilares, sejam eles dentes naturais ou implantes osseointegrados deve apresentar distribuição de forças uniforme e adaptação a mais perfeita possível, de tal forma que ocorra de forma exata e passiva" [6]. Devido à complexidade e diferentes tipos de corpos em que se deseja aplicar a prótese, é difícil se obter, mesmo que por fundição (monobloco), um componente que possua formato exato, é necessário frequentemente a utilização de secção e posterior soldagem destas peças. Esta técnica permite que se trabalhe com segmentos menores melhorando a adaptação final da prótese.

Nesse processo de soldagem de ligas de titânio para confecção de implantes, as duas técnicas mais recomendadas são a soldagem TIG (Tungsten Inert Gas), também conhecida como GTAW (Gas-Shielded Tungsten Arc Welding) e a soldagem a laser [7, 8, 9]. A soldagem TIG protege o elemento soldado da atmosfera, isto é, do oxigênio, nitrogênio e do hidrogênio. Essa característica de proteção da superfície é um dos motivos para a soldagem TIG ser escolhida para esses fins, já que o titânio possui alta reatividade química com os elementos supracitados à quente.

O titânio ASTM F67, também chamado de titânio comercialmente puro pelo seu alto grau de pureza, é um metal utilizado para próteses fixas, possuindo boa resistência à corrosão. No entanto, sob altas temperaturas, torna-se quebradiço, o que dificulta a utilização dos processos de fundição e soldagem pois de acordo com Hruska e Borelli (1991), que avaliaram os resultados de fundição do titânio com um dispositivo que evitava a contaminação do molde, o titânio comercialmente puro possui alta reatividade à nitrogênio, oxigênio e hidrogênio, em temperaturas acima de $750^{\circ} \mathrm{C},[10]$.

Além do titânio comercialmente puro, existe a liga de titânio ASTM F136 (Ti-6Al-4V), que juntamente com o F67, são os mais utilizados para a finalidade odontológica, além desses dois tipos de titânio, mais recentemente foram desenvolvidas as ligas livres de vanádio do tipo $\alpha+\beta$, como Ti-6Al-7Nb e Ti-5Al-2.5Fe, que também podem ser utilizadas para esta finalidade [11].

Baseando-se no que foi demonstrado, o presente trabalho visa propor um procedimento de ensaio de tração para as juntas soldadas de Ti voltadas ao modelo de união aplicado à montagem da prótese-protocolo que leve em conta a geometria aproximada da prótese, isto é, adaptar o ensaio de tração para que os corpos de prova com a geometria mais complexa como das próteses possa também ser submetida ao teste de tração. Para isso, também, será realizada soldas alterando a corrente empregada, para que se possa averiguar a adaptação do ensaio em diferentes parâmetros de soldagem. 


\section{REFERENCIAL TEÓRICO}

As próteses fixas (ou implantes) têm custo maior em relação as próteses removíveis overdenture - mais comumente vistas (Figura 1), por características de confecção mais difícil e com processo cirúrgico mais complexo, no entanto, as próteses totais fixas são as preferidas pelos pacientes por prover uma mastigação eficiente e firme, com poucas manutenções durante sua vida útil, além de melhorar a autoestima de quem necessita dessas próteses, uma vez que o caráter removível é eliminado [12].

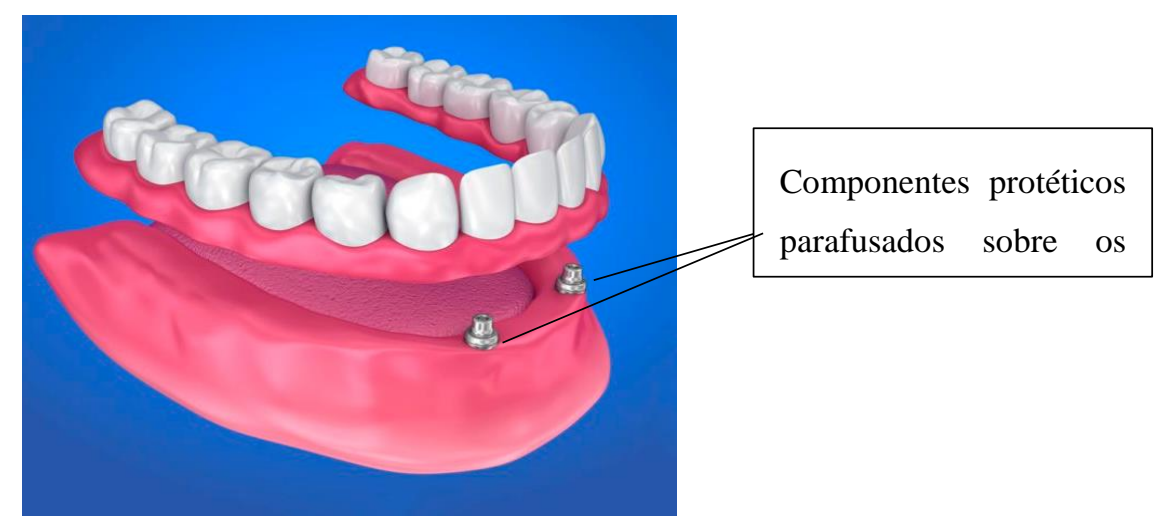

FIGURA 1. Prótese Overdenture [13].

As próteses tipo Protocolo, inicialmente desenvolvida por Branenmark, são colocadas seguindo o procedimento a seguir: entre 4 e 6 implantes na mandíbula - parte inferior da boca - (Figura 2a) e uma estrutura cantilever distal de ambos os lados para suportar os dentes molares (no final da arcada dentária), e na maxila parte superior da boca - recomenda-se 6 a 8 implantes (Figura 2b). A infraestrutura de titânio com soldas, é posta no interior das resinas que irão compor a prótese dentária [14], mostradas na Figura 2c.
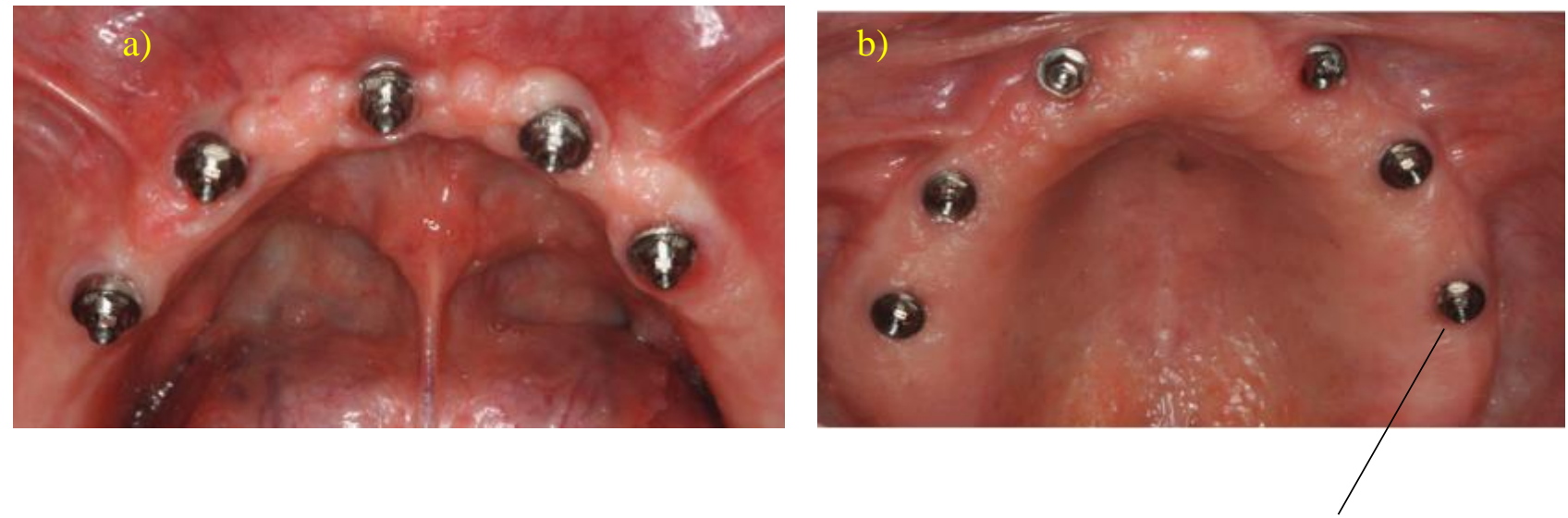


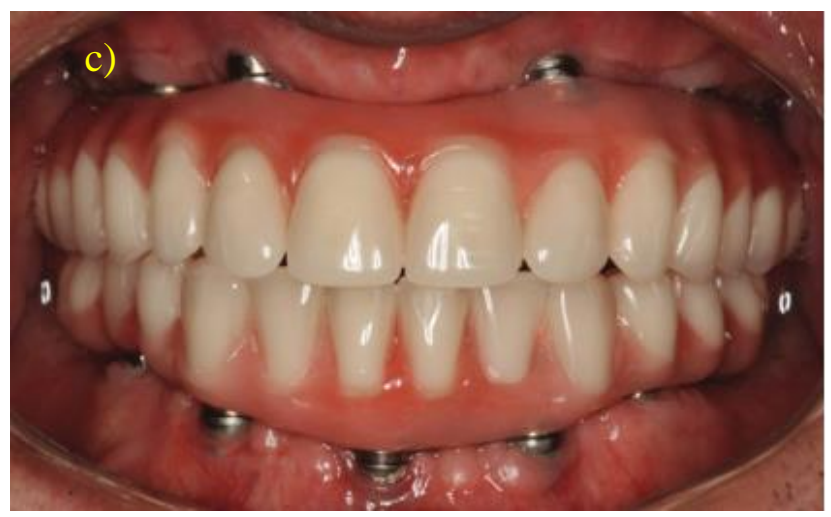

Componentes protéticos parafusados sobre o implante.

FIgURA 2. a) Prótese tipo protocolo na mandíbula, b) Prótese protocolo na maxila, c) Resina para união e dentes em resina acrílica [15].

A infraestrutura de titânio que fica por baixo da resina de união (Figura 3 e 4) é confeccionada a partir de dois métodos: fresada, utilizando um equipamento e software específicos, ou a partir de conformação e soldagem de partes menores. A principal diferença entre as duas, além da exatidão das máquinas de fresa, é o custo, sendo o preço desse equipamento extremamente elevado, fazendo com que no Brasil, o principal método de confecção de implantes seja por conformação e soldagem.

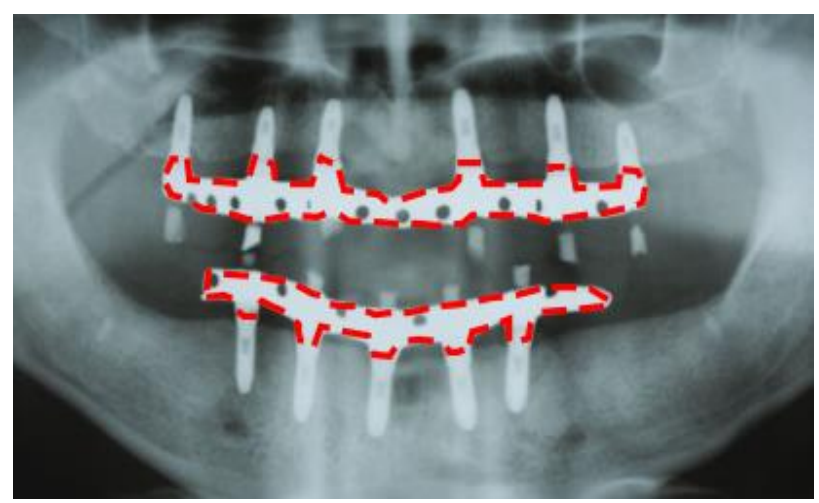

FIGURA 3: Infraestrutura de titânio em raio x [15].

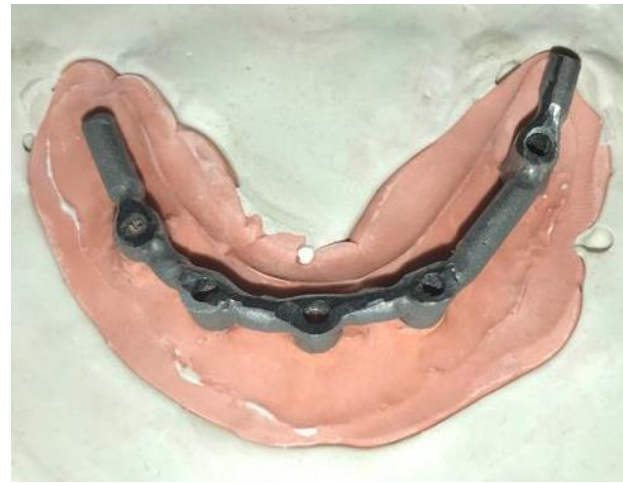

FIGURA 4. Infraestrutura de titânio soldada (Autoria própria).

Como pode ser visto nas Figuras 3 e 4, entre os segmentos da barra de titânio, existem cilindros, estes que serão responsáveis por comportar os componentes que se fixarão nos implantes da mandíbula e da maxila, vistas anteriormente nas Figuras $2 \mathrm{a}$ e 2b, sendo esses componentes responsáveis pela sustentação e retenção da prótese na boca. Portanto, nesse caso, as juntas soldadas são realizadas entre os cilindros e as hastes de titânio segmentadas.

Apesar da geometria complexa do protocolo ortodôntico, foi observado que a maioria das uniões soldadas nestes são em T, o que permitiu propor um modelo de corpo de prova soldado em T, para ensaios de tração da junta soldada nessa geometria. Para tanto, foi desenvolvido um suporte para adaptar a fixação do corpo de prova na máquina de ensaio de tração universal. 
A soldagem por arco elétrico TIG ou GTAW é usado um eletrodo não consumível de tungstênio, protegido pelo bocal da tocha, para formar a poça de soldagem [16]. De modo que A proteção realizada pelo bocal - tanto do arco, quanto da poça de soldagem, é feita por um gás inerte, podendo ser o Hélio (He) ou Argônio (Ag), que é soprado pelo bocal, como pode ser visto na Figura 5.

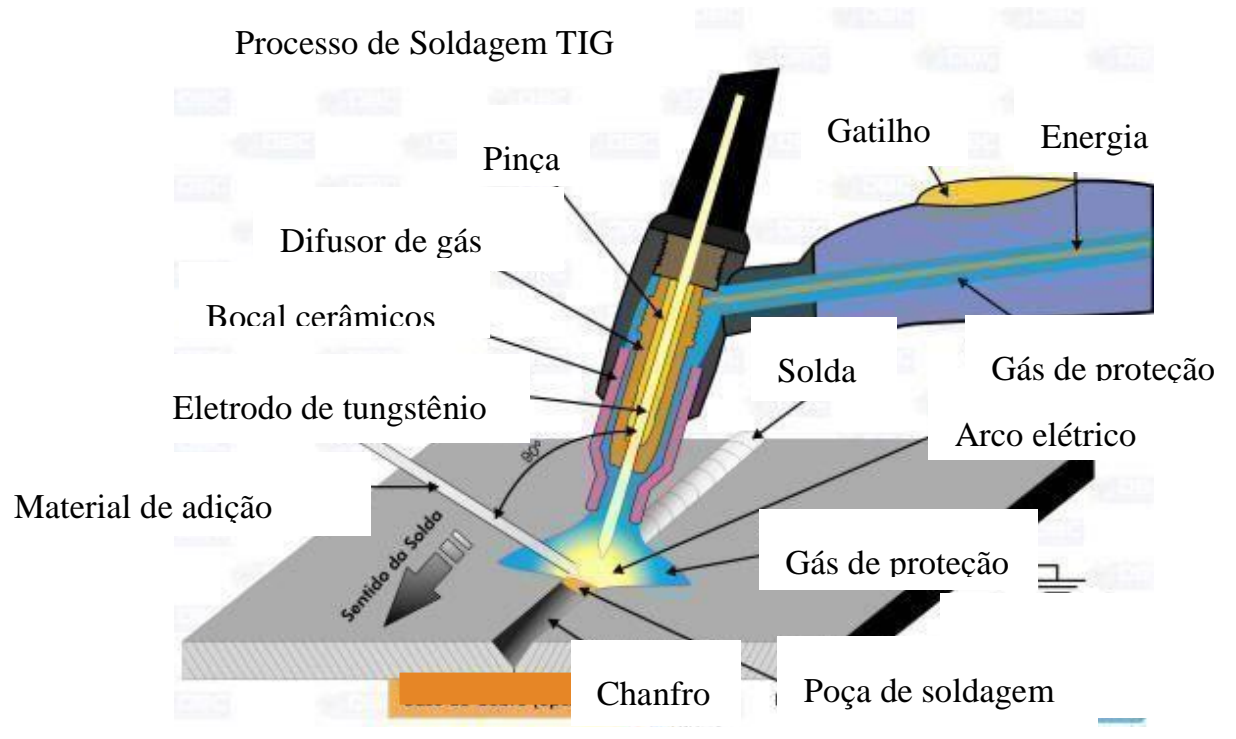

FiguRA 5. Processo de Soldagem TIG [17].

Esse processo de soldagem pode ser feito com material de adição, como na Figura 5 ou sem material de adição. Além disso, pode-se utilizar corrente alternada ou corrente contínua, sendo a contínua dividida em duas polaridades, direta (positiva) ou inversa (negativa). As polaridades, direta e inversa, diz respeito ao sentido da corrente, isto é, se a corrente vai no sentido eletrodo de tungstênio para a peça, têm-se a corrente contínua direta e se for da peça para o eletrodo, têm-se a corrente contínua inversa.

O processo de soldagem TIG apresentar um arco voltaico com uma quantidade de calor muito mais intensa que os outros processos por fusão à arco, o que permite a abertura de arcos voltaicos menores e ainda assim alcançando as temperaturas necessárias para a fusão do titânio e introduzindo uma menor quantidade de energia à junta [16]. Esse processo também permite um controle mais minucioso do deslocamento, posicionamento e controle do arco voltaico, o que faz com que seja um processo de soldagem amplamente utilizado em manutenção industrial para soldar chapas de pequenas espessuras ou diâmetros (0,2 a $8 \mathrm{~mm})$ [6]. Todavia, é um dos processos de soldagem que mais exigem habilidade e treinamento do soldador, especialmente na soldagem de materiais muito reativos, como é o caso das ligas de titânio [16].

\section{3 - Titânio puro ASTM F67}

As especificações de titânio consideradas puras regidas pela Especificação Padrão para Titânio Puro, para Aplicações de Implantes Cirúrgicos (Standard Specification for Unalloyed Titanium, for Surgical Implant Applications - ASTM F67), são divididos em 4 classes que devem conter apenas os elementos: Nitrogênio, Carbono, Hidrogênio, Ferro, Oxigênio e Titânio, sendo os demais elementos encontrados tidos como contaminantes. A Tabela 1 a seguir foi retirada da norma, na qual expõe as porcentagens máximas de cada elemento supracitado, sendo o titânio de grau 1 o com maior porcentagem de pureza e o 4 o menor. 
TABELA 1. Porcentagens de elementos no titânio puro ASTM F67 [18].

\begin{tabular}{|c|c|c|c|c|c|}
\hline & $\% \boldsymbol{N}$ & $\boldsymbol{\%} \boldsymbol{C}$ & $\boldsymbol{\%}$ & $\boldsymbol{\%} \boldsymbol{F e}$ & $\boldsymbol{\%} \boldsymbol{O}$ \\
\hline Titânio puro grau 1 & 0,03 & 0,08 & 0,015 & 0,2 & 0,18 \\
\hline Titânio puro grau 2 & 0,03 & 0,08 & 0,015 & 0,3 & 0,25 \\
\hline Titânio puro grau 3 & 0,05 & 0,08 & 0,015 & 0,3 & 0,35 \\
\hline Titânio puro grau 4 & 0,03 & 0,08 & 0,015 & 0,5 & 0,4 \\
\hline
\end{tabular}

\section{4 - Materiais e Métodos}

Uma geometria de corpo de prova é proposta aqui, a fim de permitir avaliar, por meio de ensaio mecânico de tração, se a resistência mecânica das juntas soldadas das próteses-protocolo estará compatível com as solicitações mecânicas em serviço - as forças desenvolvidas na mordida na oclusão. Os corpos de prova constituem-se de uma junta soldada em T, simulando a união entre barra e o cilindro que constituem a prótesesprotocolo. Esses CP's foram confeccionados a partir das barras ou hastes de titânio F67 de diâmetro 3,18 mm, utilizadas na produção destas próteses-protocolo.

Foram feitos cortes das hastes de titânio, para construir três CP's (Corpos de Prova) em formato de "T", como pode ser visto na Figura 7. O comprimento da haste maior e menor são, respectivamente, $80 \mathrm{~mm}$ e $25 \mathrm{~mm}$. Após o corte, foram realizadas as soldas em uma máquina de solda TIG (Inversora Origotig 150HF da marca ESAB), mostrada na Figura 6.

A fim de validar a geometria proposta para os corpos de prova, os dois primeiros corpos de prova foram soldados a uma corrente de 60 A e o terceiro a 30 A. Foram utilizados um tempo de pré e pós abertura do fluxo de argônio de 2 segundos e um eletrodo de tungstênio de $2 \mathrm{~mm}$. 


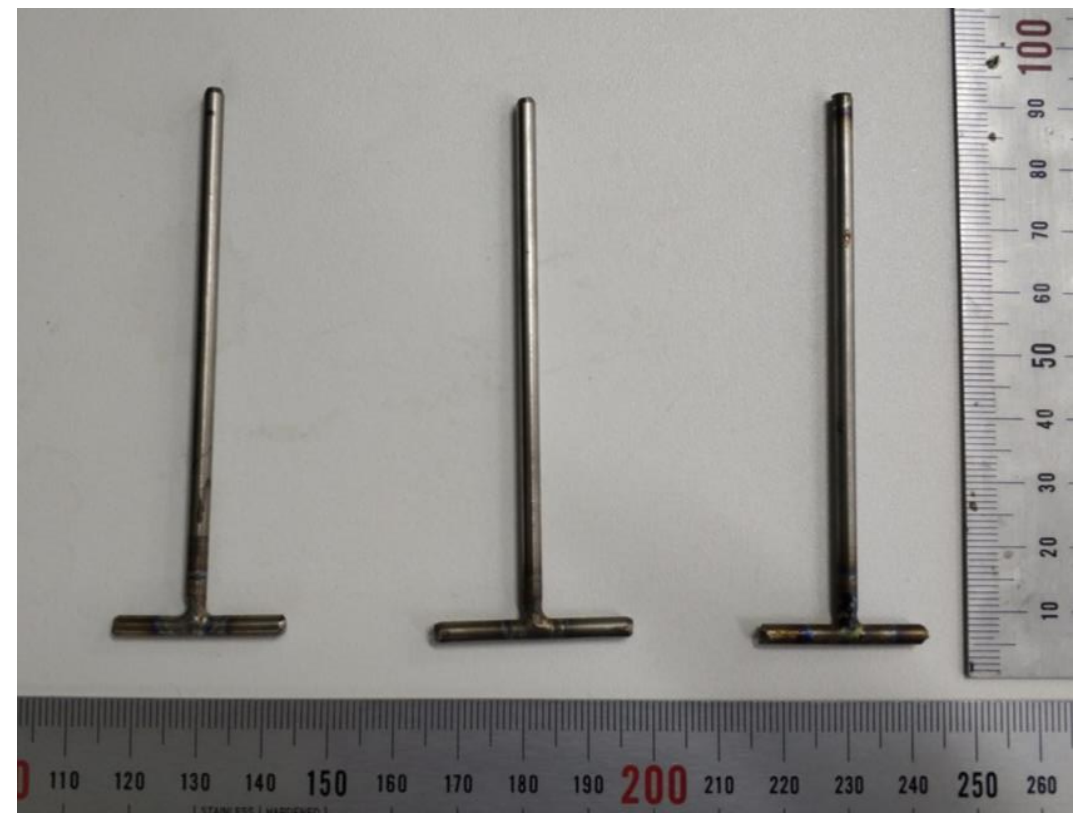

FiguRA 6. Juntas soldadas em formato de "T" (Autoria própria).

A realização de ensaios mecânicos em juntas soldadas é uma das condições pré-requisito para comparar e selecionar parâmetros de soldagem (corrente, tempo de arco aberto, vazão de gás, etc.) e procedimentos operacionais, que possibilitarão obter, posteriormente em serviço, juntas com confiabilidade e repetibilidade em termos de propriedades mecânicas. Para tanto, é demonstrado a seguir uma adaptação ao ensaio de tração, por meio de um suporte, que permitiu prender adequadamente os corpos de prova em $\mathrm{T}$ e realizar o ensaio mecânico destes, individualmente.

Foi realizado o ensaio de tração em uma máquina universal de ensaio, com a ajuda de um suporte fabricado em aço ABNT 1045, com $100 \mathrm{~mm}$ de comprimento e os rasgos de $4 \mathrm{~mm}$ de diâmetro especificamente para atender as necessidades de comportar duas hastes soldadas em formato de "T", primeiramente projetada em um software CAD $3 D$, como pode ser visto na Figura 7. Esse dispositivo, que serve como suporte para adaptar o corpo de prova soldado em T no ensaio. A adaptação do ensaio para a geometria proposta de corpo de prova soldado permite avaliar se a resistência mecânica das juntas soldadas das próteses-protocolo estarão compatíveis com as solicitações mecânicas em serviço - as forças desenvolvidas na mordida na oclusão, entre a barra e o cilindro que irão comportar as hastes para encaixe no implante feito na gengiva do paciente. 

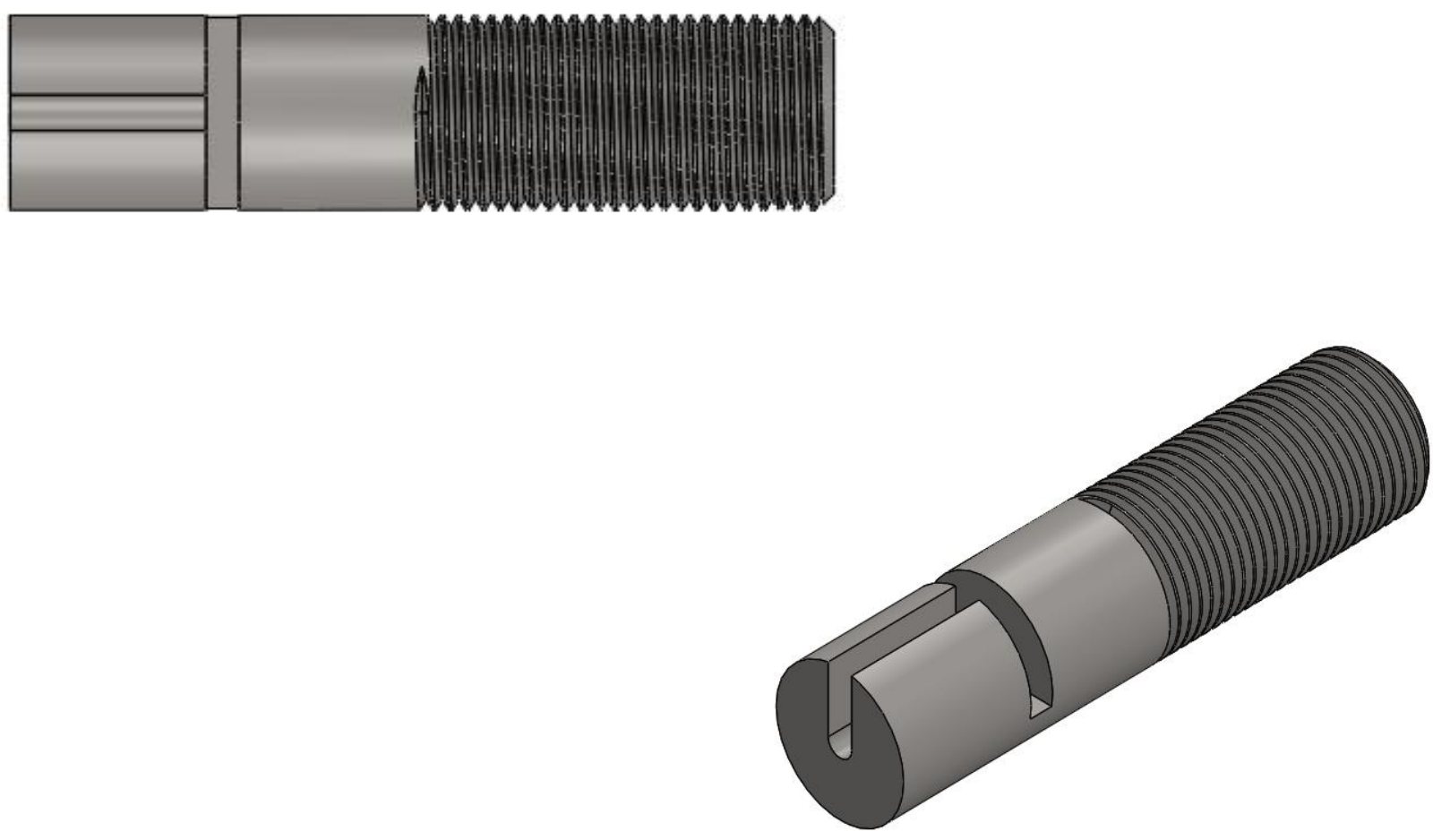

FIGURA 7. Suporte para ensaio de tração em vistas superior e isométrica (Autoria própria).

As juntas soldadas foram ensaiadas com $50 \mathrm{~mm}$ da haste maior presa pela garra, fazendo com que o comprimento útil do corpo de prova fosse de $30 \mathrm{~mm}$, como mostrado na Figura 8. O dispositivo de fixação de corpo de prova garantiu que o corpo de prova ficasse perfeitamente alinhado com o eixo central da máquina, de modo que o CP quando ensaiado sofresse somente tração pura. Além disso, a largura do rasgo (de 4mm), garantiu a não flexão do corpo de prova, aumentando a confiabilidade do ensaio.

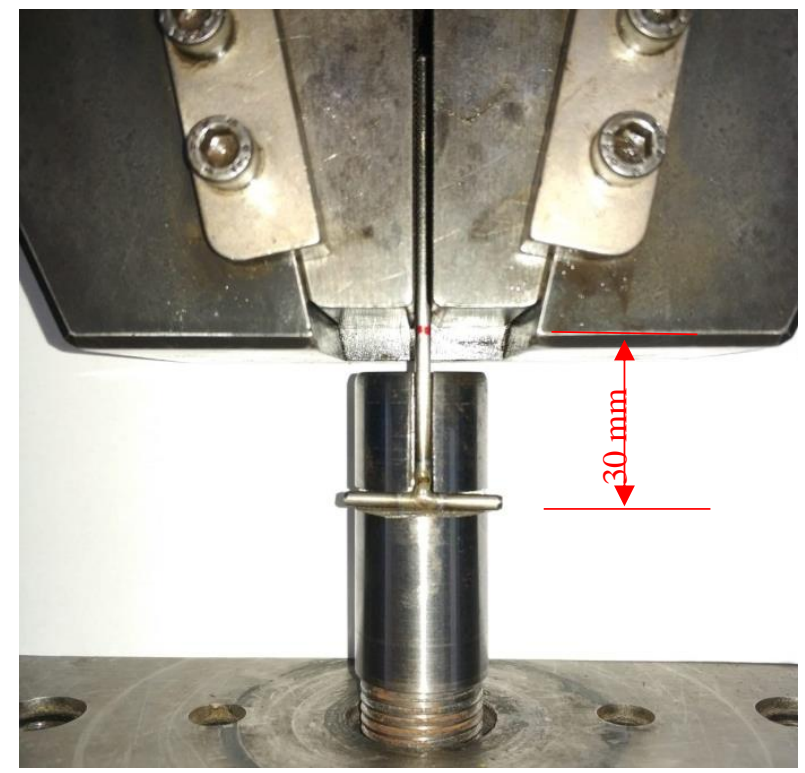

FIGURA 8. Comprimento útil para ensaio de $30 \mathrm{~mm}$ (Autoria própria).

Após os ensaios das juntas soldadas, também foi realizado o ensaio de tração com uma das hastes de $80 \mathrm{~mm}$, com o comprimento útil do corpo de prova de $20 \mathrm{~mm}$, visto na Figura 9a e na Figura 9b, esse comprimento útil 
entre as garras da máquina de ensaio. O intuito desse ensaio do metal base tem como finalidade averiguar a eficiência da solda, isto é, a porcentagem de esforço suportado pela solda com relação ao esforço necessário para a falha do metal base, isto é, o esforço para que o material escoe.
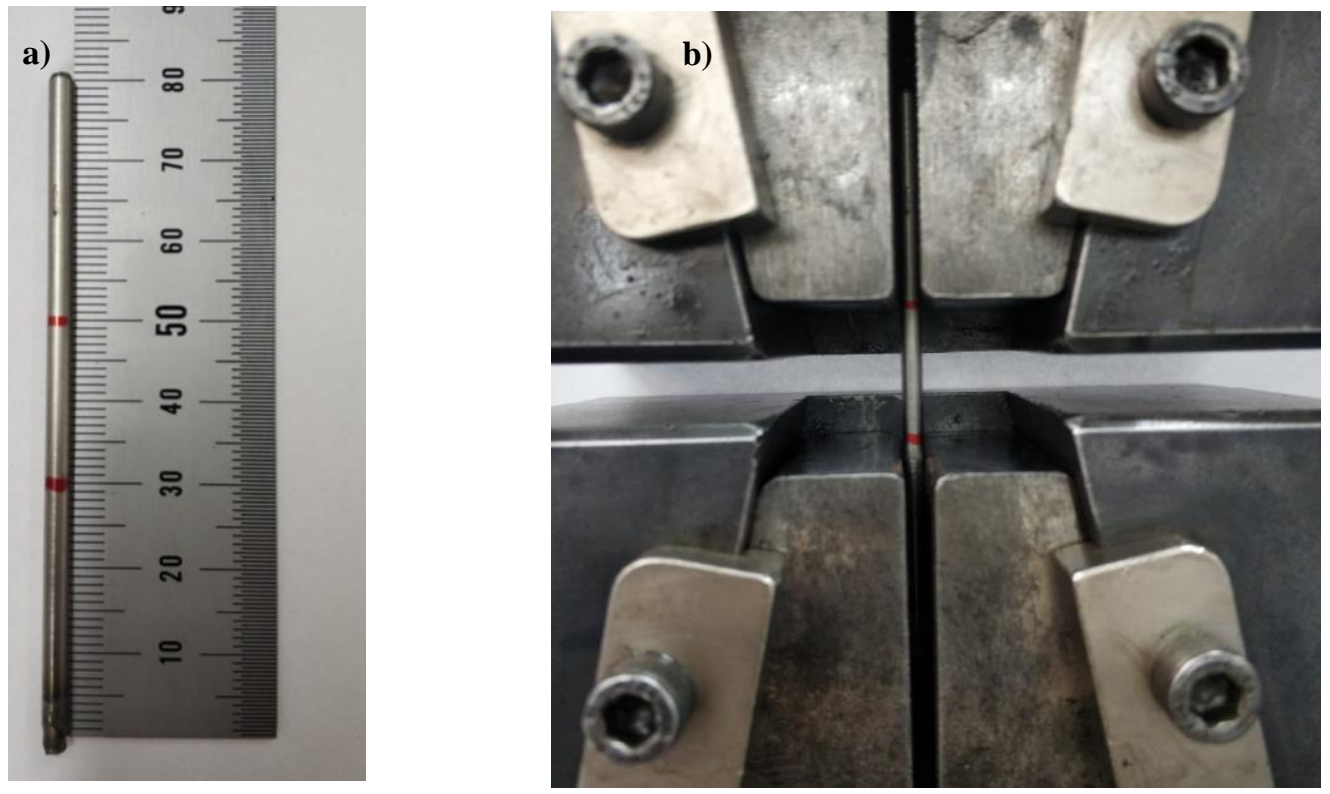

FIGURA 9. a) Comprimento útil do corpo de prova, b) corpo de prova na máquina de ensaio (Autoria própria).

\section{RESULTADOS}

Como esperado, nos três corpos de provas soldados, o rompimento ocorreu exatamente no cordão de solda, averiguado na Figura 10a, enquanto que no corpo de prova do metal base, ocorreu a fratura dúctil do tipo taça cone, visto na Figura 10b.
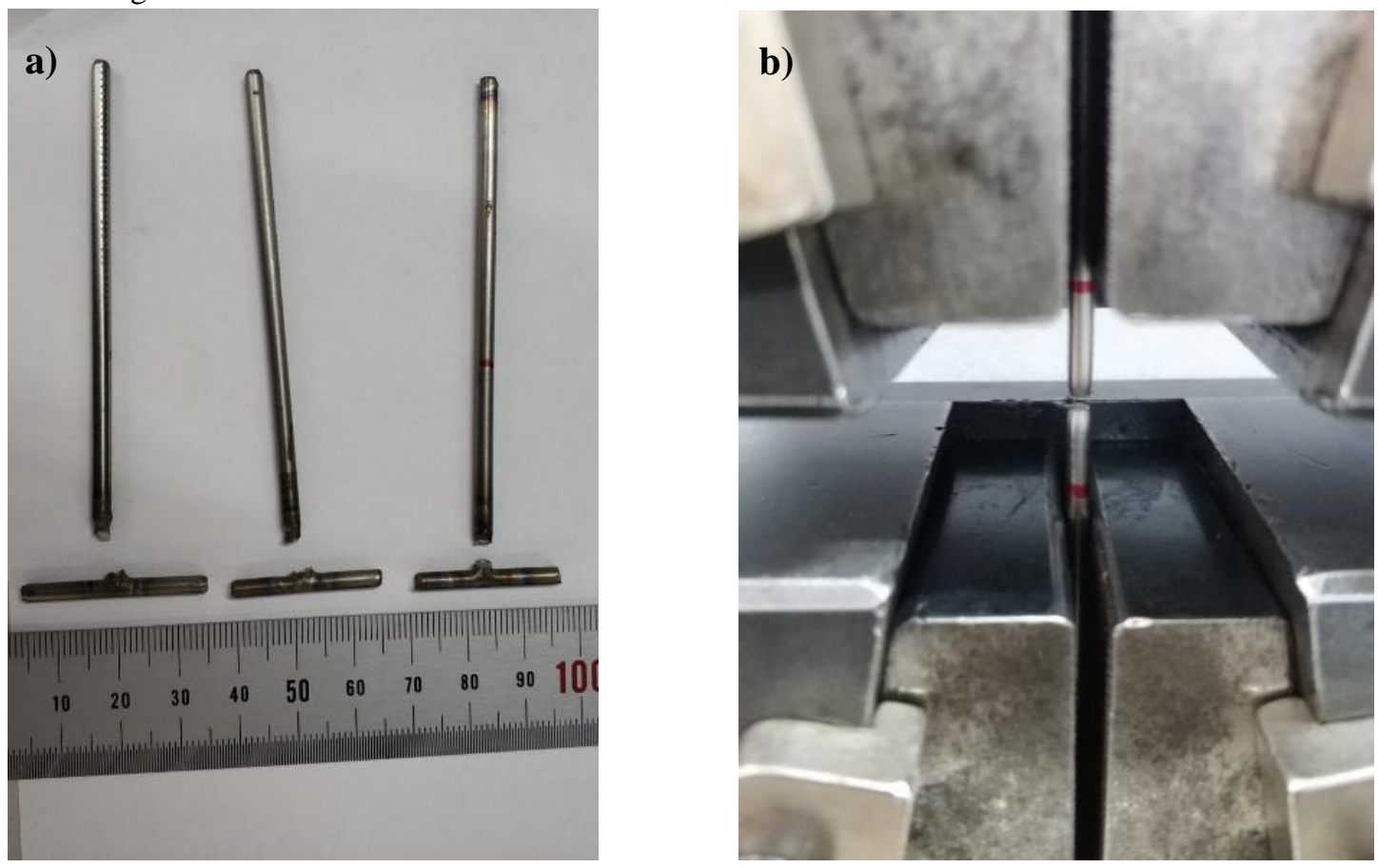

FIGURA 10. a) Corpos de prova após ensaio de tração. Da esquerda para a direita: 60 A, 60 A e 30 A (todos romperam na junta), b) Fratura dúctil de aspecto taça cone (Autoria própria). 
Para cada corpo de prova com a junta soldada foi gerado um gráfico tensão-deformação e como comparação para o valor de tensão em que as juntas romperam, também foi adicionado o gráfico do metal base, onde é possível verificar a tensão de escoamento do titânio F67, isto é, onde o metal falha.

GRÁFICO 1. Gráfico de tensão-deformação das juntas soldadas (CP 1, 2 e 3) e do metal base (Autoria própria).

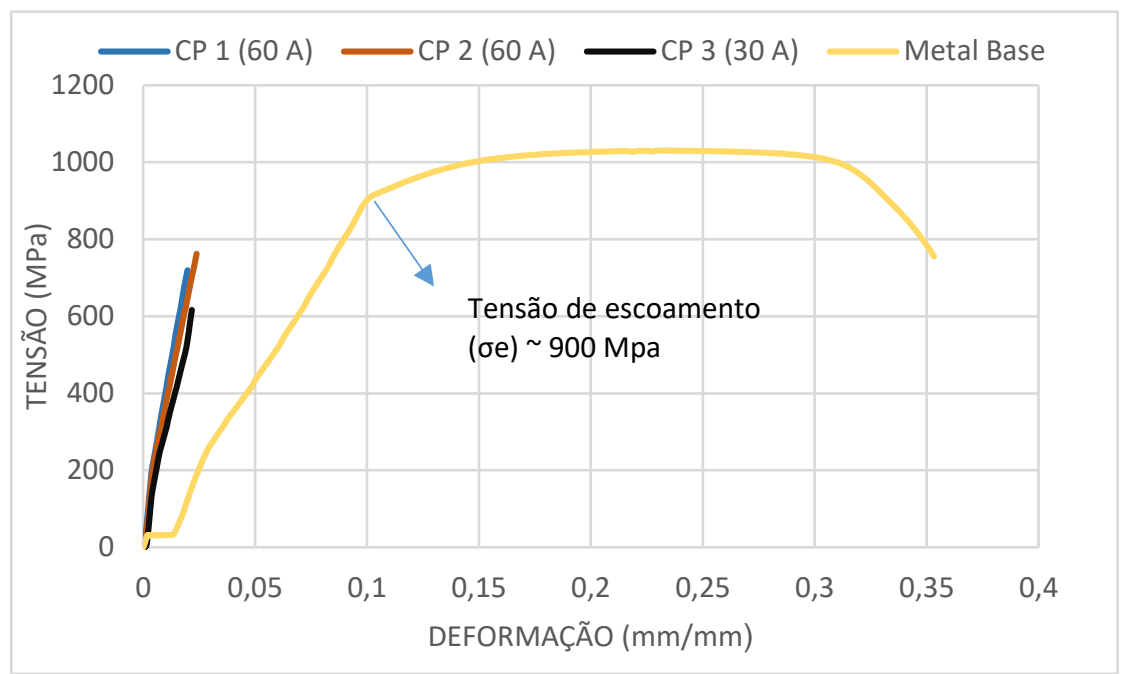

Como se pode averiguar pelo gráfico tensão-deformação, utilizando a área aproximada da seção transversal do fio de titânio com 7,94 $\mathrm{mm}^{2}$, os esforços necessários para rompimento das juntas soldadas variaram entre 4,8 kN (CP 3) e 6,0 kN (CP 2), que em comparação com o metal base atingiu entre 67 e 83\%, da força necessária para ocorrer seu escoamento. Esses valores são extremamente aceitáveis para a aplicação proposta do titânio F67, pois de acordo com Nascimento et al. (2011), a média de força máxima, encontrada na mordida humana, sem disfunções, é de aproximadamente $32 \pm 12 \mathrm{kgf}(314 \pm 118 \mathrm{~N})$ e nos dentes molares apresenta força máxima de aproximadamente $88 \mathrm{kgf}(863 \mathrm{~N})$ para homens e $69 \mathrm{kgf}(677 \mathrm{~N})$ para mulheres [19]. Sendo assim, mesmo onde ocorre a maior aplicação de força na mastigação humana (dentes molares), a solda de titânio por TIG suportaria o esforço com facilidade, comprovando a eficiência da junta soldada.

\section{CONCLUSÃO}

O Procedimento proposto aqui - corpo de prova com junta soldada em T e adaptação do ensaio de tração por meio de dispositivo especial, para validar juntas soldadas das próteses-protocolo, se mostrou satisfatório. Uma vez que, na observação visual dos ensaios, não se constatou flexão da haste horizontal do corpo de prova, quando a junta foi solicitada em tração. De modo que, as deformações observadas durante o esforço trativo do ensaio ocorreram na junta soldada e no comprimento útil do corpo de prova.

Complementarmente, com base nos ensaios de tração realizados, os resultados para os CP's soldados com corrente de 60 A foi em torno de $750 \mathrm{MPa}$ e para o CP soldado com 30 A foi de $600 \mathrm{Mpa}$.

Apesar dos resultados dos ensaios de tração para todas as juntas ensaiadas, entre $600 \mathrm{MPa}$ e $750 \mathrm{MPa}$, terem sido abaixo do Limite de Escoamento do Ti ASTM F67 (que é de $900 \mathrm{MPa}$ ), esses resultados foram considerados aceitáveis, uma vez que a máxima tensão impostas pela mordida humana nessa estrutura variam entre 85,3 e 108,7 MPa.

\section{AGRADECIMENTOS}

Agradecimentos: À clínica Dr. Alan Queiros - Implantes Dentários por ceder as barras de titânio para os ensaios. Aos Laboratórios de Soldagem e de Ensaios Mecânicos do curso de Eng. Mecânica da Ufersa, por 
disponibilizarem as instalações e equipamentos. E à Tornearia L. Lima por disponibilizar os equipamentos e materiais para confecção do dispositivo utilizado no ensaio.

\section{REFERÊNCIAS}

[1] HRUSKA, A.R. Intraoral welding of pure titanium. Quintessence Int., v. 18, n.10, p.683-688, Oct 1987.

[2] CARR AB, BRANTLEY WA. Titanium alloy cylinders in implant framework fabrication: a study of the cylinder-alloy interface. J Prosthet Dent., v. 69, n.4, p. 391-397, 1993.

[3] ODA, Y.; OKABE, T. Effect of corrosion on the strength of soldered titanium and Ti-6Al-4V alloy. Dent Mater., v. 12, n. 3, p. 167-172, May 1996.

[4] KARLSSON, S. The fit of Procera titanium crowns. An in vitro and clinical study. Acta Odontol Scand., v. 51, n. 3, p. 129-134, Jun 1993.

[5] ALBREKTSSON, T. et al. Osseointegrated titanium implants. Requirements for ensuring along-lasting, direct bone-to-implant anchorage inman. Acta Orthop Scand, v. 52, n.2, p.155-70,1981.

[6] ATOUI, J. A. Resistência Mecânica e desajuste marginal do titânio comercialmente puro submetido a dois métodos de soldagem: TIG e laser. 2008. Tese (Doutorado em Odontologia) - Faculdade de odontologia de Ribeirão Preto da universidade de São Paulo, [S. 1.], 2008.

[7] LIU J., WATANABE I., YOSHIDA K, ATSUTA M. Joint strength of laser- welded titanium. Dent Mater. 2002;18:143-8. http://dx.doi.org/10.1016/ S0109-5641(01)00033-1.

[8] WANG R.R., WELSCH G.E. Joining titanium with tungsten inert gas welding, laser welding and infrared brazing. J Prosthet Dent. 1995;74:521-30. http://dx.doi.org/10.1016/S0022-3913(05)80356-7.

[9] PIVETA A.C.G., MONTANDON A.B.A., RICCI W.A., NAGLE M.M. Mechanical strength and analysis of fracture of titanium joining submitted to laser and tig welding. Materials Research. 2012; 15: 1-7. http://dx.doi.org/10.1590/S1516-14392012005000127.

[10] HRUSKA, A. R., \& BORELLI, P. (1991). Quality criteria for pure titanium casting, laboratory soldering, intraoral welding, and a device to aid in making uncontaminated castings. The Journal of Prosthetic Dentistry, 66(4), 561-565. doi:10.1016/0022-3913(91)90524-z.

[11] NIIMONI, M. (1998). Mechanical properties of biomedical titanium alloys. Materials Science and Engineering: A, 243(1-2), 231-236. doi:10.1016/s0921-5093(97)00806-X.

[12] Calvani L, Michalakis K, Hirayama H. The influence of full-arch implant-retained fixed dental prostheses on upper lip support and lower facial esthetics: preliminary clinical observations. Eur J Esthet Dent. 2007; 2 (4): 420-8.

[13] PRÓTESE overdenture. [S. 1.]. Disponível em: https://www.dentalartepoa.com.br/sorria/overdentureprotese-dentaria-removivel/. Acesso em: 7 jan. 2020.

[14] Adell R, Lekholm U, Rockler B, Branemark P-I. A 15-year study of osseointegrated implants in the treatment of the edentulous jaw. Int. J Oral Surg. 1981; 10 (6): 387-416.

[15] ROCHA, Sicknan Soares, SOUZA, Dhiogo Ribeiro, FERNANDES, José Marcos Alves, GARCIA, Robson Rodrigues, ZAVANELLI, Ricardo Alexandre. Próteses Totais Fixas Tipo Protocolo Bimaxilares. Relato de Caso. ROBRAC, [s. 1.], 21 mar. 2010.

[16] BRACARENSE, Alexandre Queiroz. Processo de soldagem TIG - GTAW. Universidade Federal de Minas Gerais. Belo Horizonte, 2000.

[17] PROCESSO de Soldagem TIG. [S. 1.], 2014. Disponível em: http://guias.oxigenio.com/processo-desoldagem-tig. Acesso em: 14 jan. 2020 (adaptada). 
[18] ASTM F67-13(2017), Standard Specification for Unalloyed Titanium, for Surgical Implant Applications (UNS R50250, UNS R50400, UNS R50550, UNS R50700), ASTM International, West Conshohocken, PA, 2017, www.astm.org.

[19] NASCIMENTO, Gerlane Karla Bezerra Oliveira; LIMA, Leilane Maria de; RODRIGUES, Cristina Batista da Silva; CUNHA, Renata Andrade da; CUNHA, Daniele Andrade da; SILVA, Hilton Justino da. Verificação da força de mordida e da atividade elétrica dos músculos masseteres durante a mastigação em laringectomizados totais. Revista Brasileira de Odontologia, Rio de Janeiro, v. 68, ed. 2, p. 175-9, 2011. 